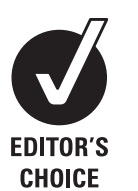

CHOICE
- Additional appendices are published online only. To view these files please visit the journal online (http://oem.bmj. com)

${ }^{1}$ TNO, Department of Quality and Safety, Zeist, The Netherlands

${ }^{2}$ Institute for Risk Assessment Sciences, Utrecht University, Utrecht, The Netherlands ${ }^{3}$ Netherlands Expertise Centre for Occupational Respiratory Disorders, Utrecht, The Netherlands

${ }^{4}$ Health and Safety Laboratory, Harpur Hill, Buxton, Derbyshire

\section{Correspondence to}

Tim Meijster, TNO, Department of Quality and Safety, PO Box 360, 3700 AJ Zeist, The Netherlands;

tim.meijster@tno.n

Accepted 5 May 2011 Published Online First 31 May 2011

\title{
Cost-benefit analysis in occupational health: a comparison of intervention scenarios for occupational asthma and rhinitis among bakery workers
}

\author{
Tim Meijster, ${ }^{1}$ Birgit van Duuren-Stuurman, ${ }^{1}$ Dick Heederik, ${ }^{2}$ Remko Houba, ${ }^{3}$ \\ Ernst Koningsveld, ${ }^{1}$ Nicholas Warren, ${ }^{4}$ Erik Tielemans ${ }^{1}$
}

\begin{abstract}
Objectives Use of cost-benefit analysis in occupational health increases insight into the intervention strategy that maximises the cost-benefit ratio. This study presents a methodological framework identifying the most important elements of a cost-benefit analysis for occupational health settings. One of the main aims of the methodology is to evaluate cost-benefit ratios for different stakeholders (employers, employees and society). The developed methodology was applied to two intervention strategies focused on reducing respiratory diseases.

Methods A cost-benefit framework was developed and used to set up a calculation spreadsheet containing the inputs and algorithms required to calculate the costs and benefits for all cost elements. Inputs from a large variety of sources were used to calculate total costs, total benefits, net costs and the benefit-to-costs ratio for both intervention scenarios.
\end{abstract}

Results Implementation of a covenant intervention program resulted in a net benefit of $€ 16848546$ over 20 years for a population of 10000 workers.

Implementation was cost-effective for all stakeholders. For a health surveillance scenario, total benefits resulting from a decreased disease burden were estimated to be $€ 44659352$. The costs of the interventions could not be calculated.

Conclusion This study provides important insights for developing effective intervention strategies in the field of occupational medicine. Use of a model based approach enables investigation of those parameters most likely to impact on the effectiveness and costs of interventions for work related diseases. Our case study highlights the importance of considering different perspectives (of employers, society and employees) in assessing and sharing the costs and benefits of interventions.

\section{INTRODUCTION}

The disease burden of work related exposures can result in high costs for employers, society and workers. For most work related diseases, dose-response relationships indicate that in order to achieve a reduction in ill-health, interventions are needed to lower workplace exposures. Quantitative health impact assessment (HIA) methods can provide a (prospective) analysis of the potential impacts of different intervention strategies on the burden of disease. ${ }^{12}$ This information may subse-

\section{What this paper adds}

- To our knowledge no previous studies have described detailed cost-benefit analyses of industry-wide occupational interventions focused on decreasing the disease burden of occupational respiratory diseases.

- One of the main aims of the developed costbenefit methodology is to facilitate the evaluation of cost-benefit ratios for different stakeholders (employers, employees and society).

- Cost-benefit analyses can provide valuable input regarding the selection of an appropriate intervention strategy and in discussions concerning who should take responsibility and meet associated costs.

- Using a model that provides a detailed description of the costs and benefits for different parties involved provides important information about the economic effects of the implementation of preventive strategies for work related diseases.

quently be used in financial evaluations that compare the costs of implementation with the benefits of the reduced disease burden (cost-benefit ratio).

These economic considerations are receiving increased attention in the decision making processes in occupational health, as organisations attempt to maximise the benefits from deploying limited resources. ${ }^{3}$ While ethical, legal and social aspects must also be considered, the strategy that maximises the cost-benefit ratio will most likely be selected. This type of analysis can also provide insight into the allocation of costs and benefits across different stakeholders. This is especially critical from the employers' perspective as they frequently cover the costs of interventions. On the other hand, the benefits extend beyond the employer and in addition to improved employee health, may include maintenance of income and reduced pressure on government and private insurance health and welfare programs. ${ }^{4} 5$

Different cost-benefit analysis methodologies have been proposed and utilised in the scientific literature. Most methodologies focus on (ergonomic-oriented) interventions at the company level. ${ }^{5-8} \mathrm{~A}$ few studies performed cost-benefit 
analysis on a larger scale, covering, for example, industrial sectors or global regions. ${ }^{9} 10$ The models and methods used in most of these studies are case-specific and thus only applicable for one health outcome or type of intervention. In public healthcare more generic models are available for cost-benefit analysis. $^{4} 11 \quad 12$ Unfortunately, these models do not provide opportunities for studying the effect of specific cost allocations and benefits for different intervention scenarios.

This study presents a methodological framework which identifies the most important elements of a cost-benefit analysis for occupational health settings. One of the main aims of the methodology is to facilitate the evaluation of cost-benefit ratios for different stakeholders (employers, employees and society (tax-payers)). The presented conceptual model for cost-benefit analysis can be seen as an extension of the quantitative HIA method described by Warren et al. ${ }^{13}$ The developed methodology is applied to a case study on work related respiratory diseases among Dutch bakery workers. Cost-benefit analyses of two interventions were performed. The first was an educational intervention that was part of a covenant. ${ }^{14}$ The second, hypothetical, scenario consisted of health surveillance followed by an individual intervention to reduce exposure for identified high risk workers. The HIA for both scenarios has been reported in an earlier paper. ${ }^{2}$

\section{DEVELOPMENT OF THE COST-BENEFIT FRAMEWORK Identification of relevant cost categories}

A review of the literature yielded various approaches to costbenefit analysis for evaluating occupational, public health and medical interventions. Published cost-benefit analyses vary greatly in scope and level of detail but do indicate the most important categories of costs and benefits of interventions. ${ }^{51015-18}$ In the Netherlands, a detailed handbook for cost studies related to healthcare issues was developed by Oostenbrink et al. ${ }^{19}$ This handbook contains a detailed overview of many relevant cost categories, data sources and calculation methods that are also appropriate for occupational cost-benefit analyses.

Figure 1 shows the conceptual framework including the relevant cost categories and their breakdown into cost elements The main cost categories identified are: costs of interventions, operating costs, health related costs, customer services and costs associated with liability and safety. We also tried to identify whether these costs should be attributed to employers, employees or society.

\section{Description of identified cost categories}

\section{Intervention costs}

The intervention costs consist of six cost elements: (1) investments (eg, machinery, technical control measures), including the costs of advice and installation; (2) training and education associated with the intervention; (3) disinvestments, that is benefits from the sale of old equipment; (4) identification of the intervention population (eg, health surveillance to identify high risk workers); (5) costs related to research activities (eg, intervention mapping or evaluations); and (6) subsidies, which benefit the employer but at the same time can be a societal cost if the subsidies are paid by the government.

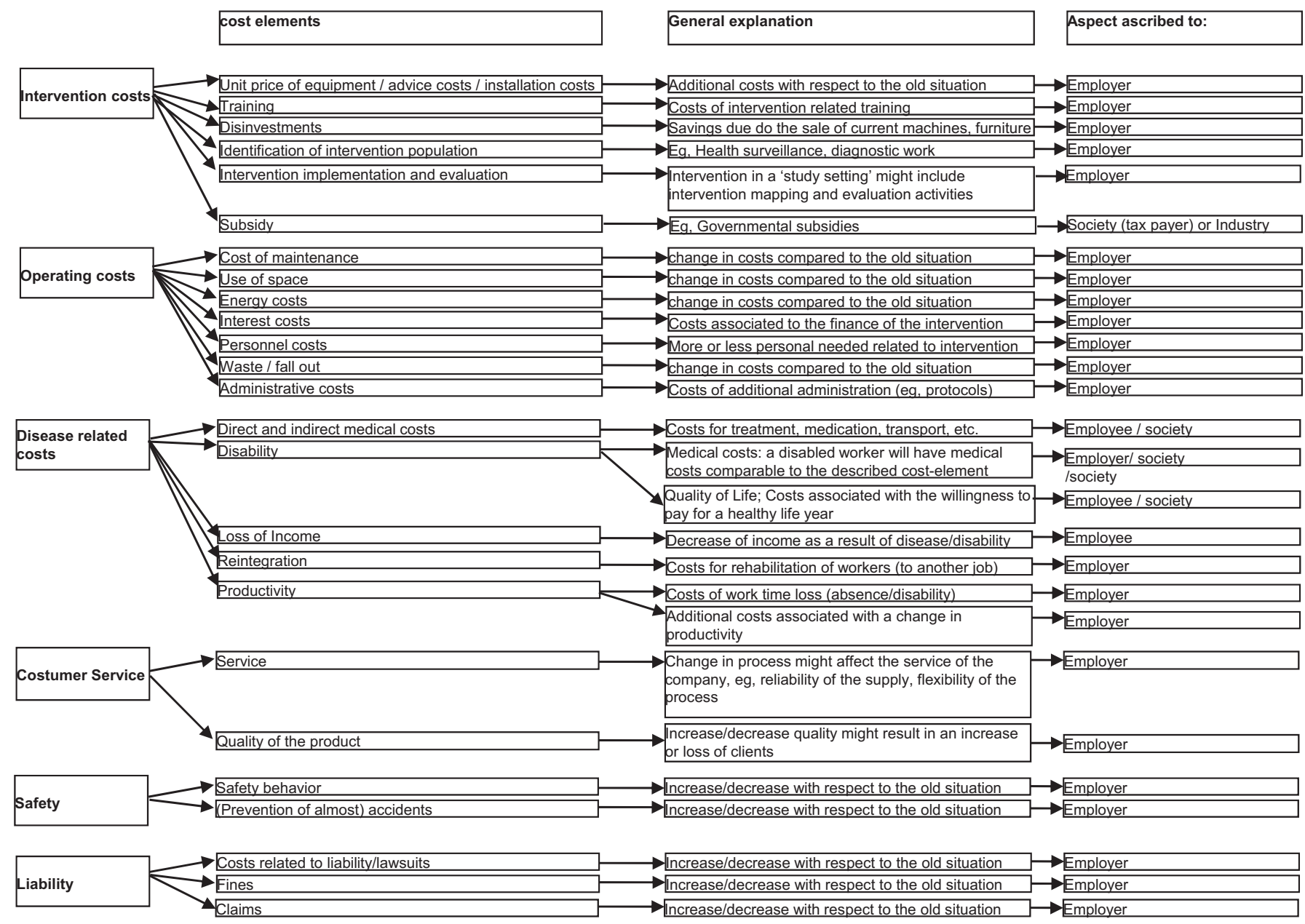

Figure 1 Schematic overview of the conceptual approach for cost-benefit-analysis. 


\section{Operating costs}

Operating costs are associated with the operational processes. Well known cost elements are administrative costs and utility costs such as those related to energy and housing (space). Other important costs are maintenance and cleaning costs and wastage/fall out. A last category, interest costs, is relevant when a company borrows money to (partially) finance an intervention.

\section{Disease related costs, productivity loss and sickness absence}

This cost category contains all cost elements directly and indirectly associated with (the change in) the disease burden resulting from interventions. A first important cost element here is direct and indirect medical costs. Direct medical costs include expenses related to medication, hospitalisation and visits to the general practitioner. Indirect costs include, for example, costs of transportation.

The second cost element, productivity loss, is associated with sickness absence but might also include productivity losses due to sick workers continuing to work (presenteeism). Traditionally this is calculated by multiplying the units of lost time by the unit salary costs (human capital method). It is nevertheless acknowledged that in most cases the true costs will depend on the way the ill worker is replaced and if productivity loss occurs. So the real costs can differ substantially. Koopmanschap et al provide a detailed overview of factors that determine if and why productivity loss due to sickness absence might be limited. ${ }^{20}$ One of the main factors is the elasticity in a company, meaning that the actual work time loss results in less productivity loss because people are not $100 \%$ efficient and some of the work might be performed by the already available work force without additional costs.

In case of chronic illness or (partial) disability, in most countries the employer has to pay the salary of the disabled worker. In the Netherlands, the employer usually has to pay the worker's wages for the first 2 years of illness or disability. Rehabilitation of the sick worker and administration involve additional costs. In the Netherlands the employee receives payments from social security funds after 2 years of disability, which continues until re-employment or age 65 (the legal pension age). In most cases the employee loses part of their income.

Longitudinal studies indicate that even if exposure ceases, asthma symptoms can persist depending on factors such as exposure duration and the causative agent. ${ }^{21} 22$ A recent review of the socio-economic effects of occupational asthma reported that $25-38 \%$ of workers with occupational asthma experience prolonged work disruption. ${ }^{23}$ (Re-)employment of a worker also depends on socio-demographic factors and the presence of a (national) re-employment program. ${ }^{23} 24$ Exact figures on the duration of work disability associated with occupational asthma are not known, although it is generally acknowledged that some affected workers are permanently disabled. ${ }^{25}$ Different follow-up studies on non-specific or occupational asthma report that $25-40 \%$ of workers were unemployed at the time of follow-up. ${ }^{26-28}$ A Dutch study on the effectiveness of employment services for work disabled adults showed that the chances of re-employment are small after the fourth year of unemployment (including chronic sickness absence). ${ }^{24}$

\section{Customer service, safety and liability}

The three remaining costs categories will for most occupational health interventions have limited impact on the cost-benefit ratio and are in many cases also less easy to quantify. Nevertheless, they may still need to be taken into account if large changes are expected as a result of a specific intervention Implementation of the intervention might effect the company's customer service. For example, speed of production, product quality, delivery reliability, flexibility and customer service might (temporarily) be affected, resulting in reduced income or compensation claims. Finally, implementation of the intervention might result in changes in the safety and liability costs of the company.

\section{DESCRIPTION OF THE COST-BENEFIT CASE STUDY Intervention scenarios}

In this cost-benefit study two previously described intervention scenarios were evaluated. ${ }^{2}$ In short, the first scenario included an industry-wide education program where individual companies were visited by consultants who supplied information on the risks of exposure and provided guidance on good work practice. The impacts of this intervention program on exposure to flour dust and the disease burden were evaluated quantitatively. ${ }^{2} 29$ The second scenario is a hypothetical health surveillance intervention program where high risk workers, defined as workers sensitised to occupational allergens and/or reporting upper respiratory symptoms, are identified through health surveillance. Health surveillance is carried out every 3 years for the full 20 -year simulation period. All workers identified receive an individual workplace intervention, which is assumed to reduce their exposures by $90 \%{ }^{2}$

The described cost-benefit analyses are based upon an assessment of the change in disease burden. A recently developed dynamic population based model for respiratory health effects in bakery workers was used to simulate the health impact of the intervention scenarios. ${ }^{13}$ The model simulates the development of disease in a fixed worker population of 10000 workers, the approximate size of the Dutch bakery population at risk, longitudinally over a period of 20 years. The model simulates the development of work related sensitisation, work related upper respiratory symptoms, work related lower respiratory symptoms and work disability in each bakery worker. Prevalence and incidence rates were extracted from the results matrices for all years and averaged over all 40 runs to correct for stochastic (population) variation. The prevalence rates were used to calculate the disease burden (eg, number of disease years) for the different outcomes.

\section{INPUT FOR THE COST-BENEFIT ANALYSIS}

The estimations of the input values are discussed by cost category. An Excel spreadsheet was used to calculate the costs and benefits for employers, employees and society by cost category. In addition, total costs, total benefits, net costs and the benefitto-costs ratio were determined.

\section{Intervention costs}

\section{Scenario 1: covenant intervention}

We obtained a detailed overview of the costs of the covenant intervention program from the initial budget and partially from the actual accredited costs. The available information attributed costs to specific stakeholders. The intervention included educational and training components and costs for the health surveillance and very limited clinical care activity. These activities were not followed by any workplace intervention but did contribute to the education of workers (eg, regarding risk perception). In total, the costs of the covenant intervention program were $€ 3438000$, of which $€ 2164000$ was paid by the employers and $€ 1274000$ by the government. A detailed overview of the costs can be found in the online appendix 1. 
Scenario 2: health surveillance and individual exposure reduction The HIA indicated that approximately 4200 high risk individuals would be identified over a 20 -year period, resulting in a similar number of individual interventions. ${ }^{2}$ The content of these interventions and thus the costs will vary substantially. The exact interventions and their impact will depend on the characteristics of the workplace (eg, whether or not controls are already in place) and the number of workers possibly benefitting from the same intervention. The anticipated interventions may involve engineering controls (eg, local exhaust ventilation), administrative controls (eg, training) and personal protective equipment. The available information does not permit calculation of a reliable estimate of the costs of individual interventions. We used the cost-benefit analysis to estimate the maximum acceptable intervention costs per sick worker based upon the projected benefits of the estimated reduction in disease burden.

\section{Operational costs}

We assumed that operational costs were not substantially affected by the intervention scenarios evaluated in this study. There might be small differences in energy use and the amount of waste/cleaning, but these are expected to cause marginal changes in costs. Also, no large additional administrative burdens are expected for either industry or regulators. It was therefore decided to omit this cost category from the final cost-benefit analyses for both scenarios.

\section{Disease related costs}

The HIA provided data on the number of sick workers and the case rates for all disease conditions. This allowed the number of disease years for the different outcomes over the complete evaluation period to be calculated. The number of disease years for disability could not be obtained directly from the HIA since disabled workers leave the simulated worker population. Here we used the total number of 'new' cases to estimate the costs, as will be described in detail below. Table 1 provides information on the changes in disease burden for the two intervention scenarios. One specific result is the increase in rhinitis symptoms for the health surveillance intervention. The majority of the high risk workers are only identified after they have developed upper respiratory symptoms. Their exposure is then reduced and as a result so is their likelihood of progressing to the next disease stage. As a consequence, workers are less likely to change to another disease state resulting in an increase in disease years for upper respiratory symptoms.

\section{Direct and indirect medical costs}

Medical costs, sickness absence and productivity loss associated with the disease burden were estimated so that the cost of the disease burden could be calculated. The Dutch National Institute for Public Health and the Environment published a report in 2004 on the costs of asthma and chronic obstructive pulmonary disease. ${ }^{18}$ The total direct medical costs of asthma per patient are expected to increase from $€ 311$ to $€ 737$ between
2000 and 2020. We used the average of $€ 524$ per patient in our calculations. An annual cost of $€ 321$ has been estimated for indirect (non-compensated) costs, such as transportation. ${ }^{30}$ Less detailed information on costs is available for upper airway symptoms. Direct medical costs for allergic rhinitis are estimated to be $€ 41$ per patient annually, and cover drug costs, general practitioner visits and hospital treatments. ${ }^{31}$ No data are available for non-compensated costs, but assuming a comparable relative contribution of these costs as for asthma symptoms, an estimate of $€ 30$ per patient annually is reasonable. All these costs were available for general asthma and rhinitis and not for specific occupational symptoms.

\section{Productivity loss}

No Dutch data are available on the number of days a worker with occupational rhinitis or asthma is absent from work as a result of their illness. Some studies on occupational asthma report the costs of work time loss but most do not specify exactly how these costs were assessed. ${ }^{32} 33$ Some international studies on asthma in the general population do report on work absenteeism as a consequence of asthma. ${ }^{34-37}$ Although these studies do not consider work related asthma specifically, they do provide an indication of the work time loss due to asthma symptoms. The estimates range from 1 to 28 days of absence with average values of between 4 and 10 days. The UK Health and Safety Executive reported that between 5.5 and 28 work days were lost in 2008/2009 as a result of occupational respiratory symptoms. It is likely that the sickness absence figures for general asthma underestimate sickness absence due to occupational asthma, since here the causal factor is exposure in the workplace. Based upon the available information, an average of 10 work days lost per working year for an individual with occupational asthma in this sector seems a reasonable estimate.

For rhinitis less evidence is available on the link between illness and absence from work. Two US studies estimated 0.34 and 3.6 lost work days per year as a result of allergic rhinitis in the general (working) population. ${ }^{38} 39$ It is likely that, as for occupational asthma, work related allergic rhinitis is more severe during work activities and thus results in more work days lost than allergic rhinitis associated with common allergens. We estimate that work related rhinitis results in an average of 5 lost work days per annum.

To estimate the cost of lost work days, the costs of 1 work day were calculated. An average daily wage was calculated based on information obtained from the collective labour contract and including additional costs (social security, insurance and pension). This figure was then corrected for the average elasticity figure of 0.8 obtained from Koopmanschap et al, ${ }^{20}$ meaning that for every $1 \mathrm{~h}$ of absence productivity decreases by the equivalent of $0.8 \mathrm{~h}$. The cost of a lost work day was calculated as $€ 202$.

\section{Work disability}

We assumed the incidence of new disability cases would be equally divided over the full 20 -year simulation period. Given the

Table 1 Number of new cases and disease years of workers with rhinitis and asthma symptoms and of disabled workers calculated with the dynamic population-based health model with or without implementation of interventions for a worker population of 10000 workers over a period of 20 years

\begin{tabular}{|c|c|c|c|c|c|c|}
\hline & \multicolumn{2}{|c|}{ No intervention } & \multicolumn{2}{|c|}{ Covenant intervention } & \multicolumn{2}{|c|}{ Health surveillance intervention } \\
\hline & New cases & Disease years & New cases & Disease years & New cases & Disease years \\
\hline Rhinitis symptoms & 2436 & 20591 & 2026 & 19012 & 1890 & 23021 \\
\hline Work disability & 555 & - & 469 & - & 333 & - \\
\hline
\end{tabular}


Table 2 Number of prevented disability years per category for both intervention scenarios

\begin{tabular}{llc}
\hline Prevented disability years & $\begin{array}{l}\text { Covenant } \\
\text { intervention }\end{array}$ & $\begin{array}{l}\text { Health surveillance } \\
\text { intervention }\end{array}$ \\
\hline First and second years & 154 & 397 \\
Third and fourth years & 86 & 222 \\
$>4$ years & 181 & 468 \\
Total & 421 & 1086 \\
\hline
\end{tabular}

above information, we assumed for our population that approximately $70 \%$ of disabled workers are re-employed in the first 4 years of work disability. We also assumed that workers who are still unemployed after 4 years do not return to work. As a result we estimated that $82.5 \%, 65 \%, 47.5 \%$ and $30 \%$ of disabled workers would still be disabled after the first, second, third and fourth years, respectively. After 4 years the number of disabled workers was assumed not to decrease any further. Finally, all disability years were added up to estimate the total number of disability years for the full simulation period. Appendix 2 (online) provides the detailed calculations of disability years. Table 2 shows the number of prevented disability years for both intervention scenarios.

We assumed that the direct medical costs of disabled workers were similar to those of patients with asthma. Specific arrangements stipulated by the collective labour agreement were taken into account when the costs of absence were calculated. In the first year of disability the employee receives $100 \%$ of his/her wages, $95 \%$ in the second year, $85 \%$ in the third and fourth years and $75 \%$ in following years. For the first 2 years the wages are fully paid by the employer, while in the third and fourth years the employer pays $5 \%$ and the rest is paid by the social security office. In addition to salary costs, re-integration costs for the disabled employee are paid by both the employer and society. An re-integration program for a disabled worker is estimated to cost $€ 3250 .{ }^{24}$ One program for each disability case was assumed and costs were assigned to society. The last cost element is the loss of income of the employee, as described above.

\section{RESULTS OF THE COST-BENEFIT ANALYSIS}

\section{Results for scenario 1: covenant intervention program}

An overview of the costs and benefits for the different cost categories and for the employer, employee and the society, is presented in table 3. Overall, implementation of the covenant intervention program resulted in a benefit of $€ 16848546$ over a period of 20 years for a population of 10000 workers. Implementation of the intervention is cost-effective for all parties.

\section{Results for scenario 2: health surveillance intervention}

Table 3 shows the benefits for the main cost categories for scenario 2. Overall, there was an estimated benefit of $€ 44659352$ for the full 20-year period for a population of 10000 workers. A total of 4200 individual interventions was estimated. Based on these figures the average cost of an individual intervention needs to remain below $€ 10000$ per intervention for there to be a net benefit. If the interventions are fully paid for by the employers, the average cost must remain below $€ 4650$ per individual intervention so as not to exceed the employer's benefits. However, it should be acknowledged that in many cases workplace changes are likely to affect more than one worker and changes will also impact on future workers, which further complicates the assessment of intervention costs at an individual level.

\section{SENSITIVITY ANALYSIS}

We performed a local sensitivity analysis to assess the robustness of our cost-benefit model. The inputs of our cost-benefit calculation were changed by $5 \%$ for each calculation and the impact of this on our outcome values evaluated. We performed this analysis for the covenant intervention only since all inputs were only available for the cost-benefit model. We expressed the output as a sensitivity score which was calculated by dividing the $\%$ change in our output value by the $5 \%$ change. In figure 2 we present the sensitivity score for the different input parameters of our model. As expected, the sensitivity of our outcome varies substantially depending on the input parameter. The outcome is most sensitive to the input values for the number of disease years of asthma and disability as well as the estimation of the cost of a work day.

\section{DISCUSSION}

Cost-benefit analyses of intervention policies in the field of occupational health are scarce. Published approaches vary substantially between studies as do the data requirements and level of detail. As no 'off the shelf' model or methodology was available for this study, a framework was developed based on earlier work and expert input. It became very clear that the details of cost-benefit analyses will vary between studies and countries. However, the general framework will apply to most occupational interventions, even in an international context.

The present study shows how cost-benefit analyses might be used to establish if an intervention strategy will lead to (long term) monetary benefit for different stakeholders or to determine what acceptable intervention costs might be. The analysis of the covenant scenario shows how a relatively limited

Table 3 Costs and benefits for the main cost categories and for the different stakeholders for both intervention scenarios

\begin{tabular}{|c|c|c|c|c|c|}
\hline Scenario & Cost category & Society & Employers & Employees & Total \\
\hline Covenant & Costs of intervention & $-€ 1274000$ & $-€ 2164000$ & -- & $-€ 3438000$ \\
\hline intervention & Avoided medical costs & $€ 1376835$ & - & $€ 851154$ & $€ 2227989$ \\
\hline \multirow[t]{4}{*}{ scenario } & Avoided absence & - & $€ 5802450$ & - & $€ 5802450$ \\
\hline & Avoided disability costs & $€ 6098538$ & $€ 4393793$ & - & $€ 10492331$ \\
\hline & Avoided loss of income & - & - & $€ 1763776$ & $€ 1763776$ \\
\hline & Total net benefit & $€ 6201373$ & $€ 8032243$ & $€ 2614930$ & $€ 16848546$ \\
\hline Health & Costs of intervention & Unknown & Unknown & Unknown & Unknown \\
\hline surveillance & Avoided medical costs & $€ 3183690$ & & $€ 1983105$ & $€ 5166795$ \\
\hline \multirow[t]{4}{*}{ scenario } & Avoided absence & & $€ 8290080$ & & $€ 8290080$ \\
\hline & Avoided disability costs & $€ 15317113$ & $€ 11327283$ & & $€ 26644396$ \\
\hline & Avoided loss of income & & & $€ 4558081$ & $€ 4558081$ \\
\hline & Total net benefit & Unknown & Unknown & Unknown & Unknown \\
\hline
\end{tabular}




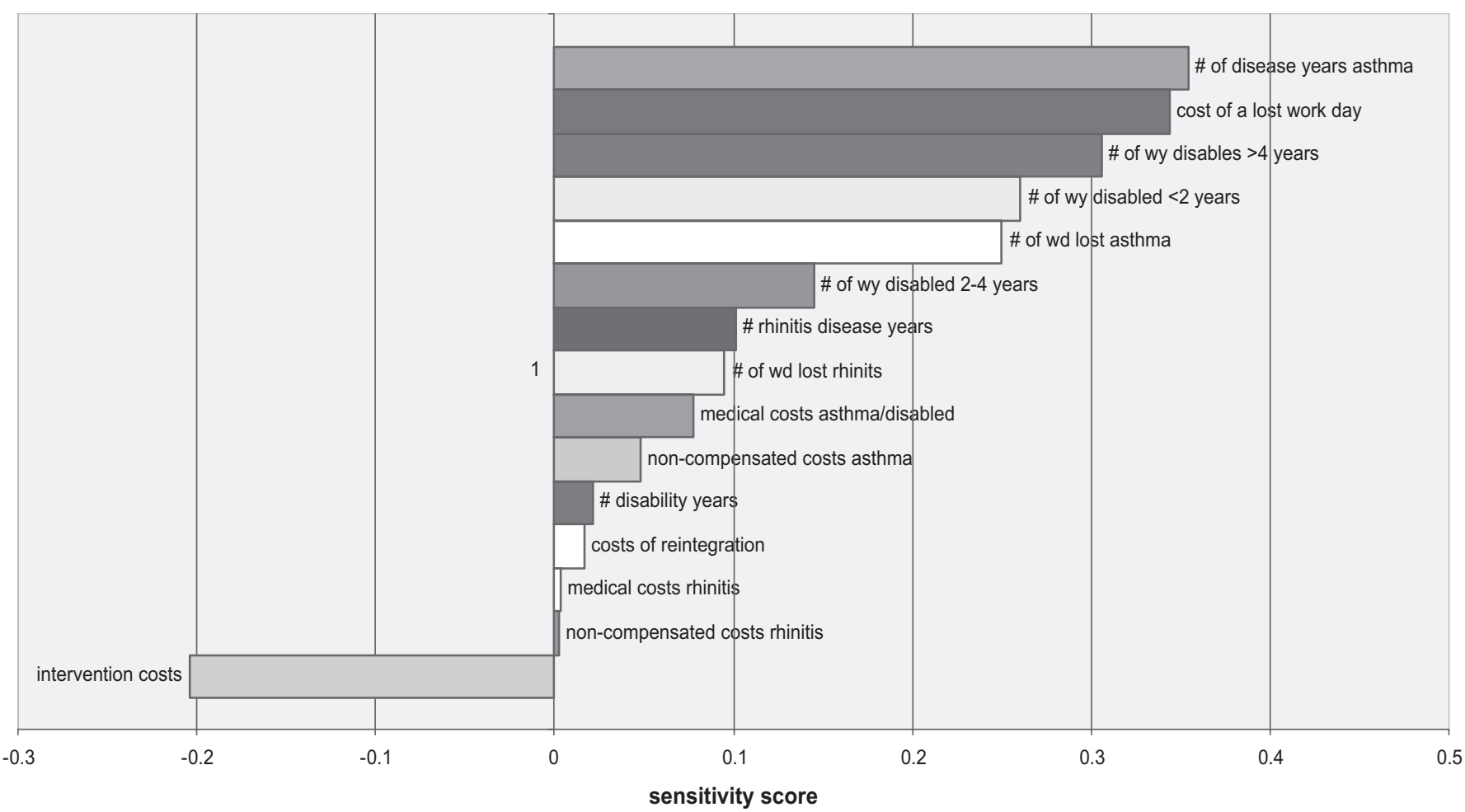

Figure 2 Tornado plot of sensitivity analysis for all cost-benefit analysis input parameters. wd, work day; wy, work year.

reduction in disease burden can still be cost-effective. The analysis of the health surveillance scenario shows how the distribution of benefits and costs over different stakeholders may lead to very different costs.

We believe that cost-benefit analyses, as performed in this study, can provide valuable input both for the selection of an appropriate intervention strategy and for discussions concerning who should take responsibility and meet associated costs. The, not unexpected, finding that costs and benefits are unequally shared, supports the observation that employers sometimes have few (financial) incentives to implement intervention strategies as the benefits (that overall are greater than the costs) extend beyond the employer. This insight into the distribution of costs and benefits may facilitate discussion about alternative cost sharing mechanisms. For example, a government might decide to subsidise employers in order to encourage implementation of an effective intervention, as was actually done in the Dutch covenant example, but may also base the scale of subsidies on exercises such as this cost-benefit analysis.

An important limitation of the cost-benefit analyses in this study is the fact that uncertainty is not included. For all inputs, point estimates were obtained from different information sources, several of which include substantial uncertainty. However, in many cases it should to be possible to include additional information in the form of ranges or distributions that represent this uncertainty. This is, for example, the case for the inputs relating to disease and disability years, where confidence intervals can be directly obtained from the dynamic population model. In order to include uncertainty, the calculation tool should be transformed to a probabilistic model assessing an output distribution of cost by means of, for example, Monte Carlo simulation.

It was difficult to obtain the true costs for every element in the cost-benefit framework, for example, the medical costs of occupational rhinitis and asthma had to be estimated from Dutch cost data on general asthma or from data for occupational asthma in other countries. For the costs of sickness absence it is, as stated, likely that work related (allergic) diseases result in higher sickness absence. Consequently, it was decided to use absence figures at the high end of ranges reported in general population studies. On the other hand, although we did take into account the effect elasticity will have on the costs of sickness absence, we were unable to use the full friction cost method for our calculations since the compensation mechanism is not completely understood. There might also be a friction component for disability at a societal level when disabled workers are replaced with currently unemployed workers. In this case the costs of disability might (partially) be compensated by benefits from lower unemployment costs. Since the size of this effect it unknown, we choose to use the human capital method and assign full costs. The preferred method of calculation will mainly be determined by the compensation system, which might differ by country and by industry.

In addition we did not take into account productivity loss due to ill workers being less productive at work (presenteeism). No information on this is available in the literature, but we believe that the allergic respiratory diseases modelled here would actually prevent symptomatic workers from going to work.

The sensitivity analysis showed that the model is fairly robust to deviations in our input parameters. In addition the input parameters to which the model is most sensitive, especially the number of disease years for asthma and the costs of a lost work day, are underpinned by high quality epidemiological data and specific income data from labour agreements. Regarding the input from the health impact model, a detailed sensitivity and uncertainty analysis can be found in the paper by Warren et $a .^{13}$ For some of the input variables for which information was scarce, such as the cost information for rhinitis, the sensitivity of the model is limited. One specific issue is that results 
are probably quite sensitive to how long workers are disabled. So more information on the likelihood of becoming disabled due to asthma, and the duration of the disability before re-integration, and how many workers are actually permanently disabled, is urgently needed, especially given that currently these are some of the least understood aspects of occupational asthma.

In general, estimation of the effect of an exposure-oriented intervention can be problematic. As exposure may be reduced immediately or more gradually over time, the chosen scenario greatly determines the health impact of an intervention. Second, after implementation of an intervention there is usually only a limited impact on the population disease burden in the short term. The greatest impact occurs after several years (or even decades) depending upon latency and rate of disease progression. In these cases, costs and benefits should be calculated over a long period as otherwise the health benefits will be underestimated. A drawback of this is that factors like indexation (not taken into account in our analyses) are likely to play an important role in the estimation of actual costs over time. In addition, it was not possible to determine the price year for all our inputs, so in general we tried to obtain the most recent available information for all parameters.

These cautionary notes notwithstanding, this study provides important insights and guidance into developing strategies for the implementation of effective exposure based interventions in the field of occupational medicine. Using a model based approach enables further investigation of those parameters most likely to impact on the effectiveness and costs of interventions for work related diseases. Our case study highlights the importance of considering the different perspectives of employers, society and employees in assessing and sharing the costs and benefits of interventions.

\section{Competing interests None.}

Provenance and peer review Not commissioned; externally peer reviewed.

\section{REFERENCES}

1. Veerman JL, Barendregt JJ, Mackenbach JP. Quantitative health impact assessment: current practice and future directions. J Epidemiol Community Health 2005:59:361-70.

2. Meijster T, Warren ND, Heederick D, et al. What is the best strategy to reduce the burden of occupational asthma and allergy in bakers? Occup Environ Med 2011;68:176-82.

3. Burdorf A. Economic evaluation in occupational health-its goals, challenges, and opportunities. Scand J Work Environ Health 2007;33:161-4.

4. Murray CJ, Evans DB, Acharya A, et al. Development of WHO guidelines on generalized cost-effectiveness analysis. Health Econ 2000;9:235-51.

5. Lahiri S, Gold J, Levenstein C. Net-cost model for workplace interventions. J Safety Res 2005:36:241-55.

6. Amador-Rodezno R. An overview to CERSSO's self evaluation of the cost-benefit on the investment in occupational safety and health in the textile factories: "a step by step methodology". J Safety Res 2005;36:215-29.

7. Koningsveld EA, Dul J, Van Rhijn GW, et al. Enhancing the impact of ergonomics interventions. Ergonomics 2005:48:559-80.

8. Oxenburgh $\mathbf{M}$, Marlow P. The productivity assessment tool: computer-based cost benefit analysis model for the economic assessment of occupational health and safety interventions in the workplace. J Safety Res 2005;36:209-14.

9. Wild DM, Redlich CA, Paltiel AD. Surveillance for isocyanate asthma: a model based cost effectiveness analysis. Occup Environ Med 2005;62:743-9.

10. Lahiri S, Levenstein C, Nelson DI, et al. The cost effectiveness of occupational health interventions: prevention of silicosis. Am J Ind Med 2005;48:503-14.

11. Oostenbrink JB, Rutten-van Molken MP, Monz BU, et al. Probabilistic Markov model to assess the cost-effectiveness of bronchodilator therapy in COPD patients in different countries. Value Health 2005;8:32-46.
12. Feenstra TL, Hamberg-van Reenen HH, Hoogenveen RT, et al. Cost-effectiveness of face-to-face smoking cessation interventions: a dynamic modeling study. Value Health 2005;8:178-90.

13. Warren N, Meijster T, Heederik D, et al. A dynamic population-based model for the development of work-related respiratory health effects among bakery workers. Occup Environ Med 2009;66:810-17.

14. Meijer E, Suarthana E, Rooijackers J, et al. Application of a prediction model for work-related sensitization in bakery workers. Eur Respir J 2010;36:735-42.

15. Driscoll T, Nelson DI, Steenland K, et al. The global burden of disease due to occupational carcinogens. Am J Ind Med 2005;48:419-31.

16. Driscoll T, Nelson DI, Steenland $\mathrm{K}$, et al. The global burden of non-malignant respiratory disease due to occupational airborne exposures. Am J Ind Med 2005:48:432-45.

17. Koningsveld EA. Participation for understanding: an interactive method. J Safety Res 2005:36:231-6.

18. Hoogendoorn EJI, Feenstra TL, Rutten-van Molken MP. Inventarisatie van het gebruik en de kosten van zorg voor astma en COPD in Nederland [Resource Use and Costs of Care for Treating Asthma and COPD in the Netherlands](in Dutch). RIVM report no 260604001. Bilthoven, National Institute for Public Health and the Environment (RIVM), 2004.

19. Oostenbrink JB, Bouwmans CAM, Koopmanschap MA, et al. Handleiding voor kostenonderzoek, methoden en richtlijnprijzen voor economische evaluaties in de gezondheidszorg [Handbook for Cost Studies, Methods and Guidelines for Economic Evaluation in Health Care.] (updated version 2004, in Dutch). The Hague: Health Care Insurance Council, 2004.

20. Koopmanschap MA, Rutten FF, van Ineveld BM, et al. The friction cost method for measuring indirect costs of disease. J Health Econ 1995;14:171-89

21. Rachiotis G, Savani R, Brant A, et al. Outcome of occupational asthma after cessation of exposure: a systematic review. Thorax 2007;62:147-52.

22. Perfetti L, Cartier A, Ghezzo H, et al. Follow-up of occupational asthma after removal from or diminution of exposure to the responsible agent: relevance of the length of the interval from cessation of exposure. Chest 1998;114:398-403.

23. Vandenplas $\mathbf{0}$, Toren K, Blanc PD. Health and socioeconomic impact of work-related asthma. Eur Respir J 2003:22:689-97.

24. Kok L, Hollanders D, Hop JP. Kosten en baten van reïntegratie [Costs and Benefits of Reintegration](in Dutch). Amsterdam: SEO economic research, 2006.

25. Blanc PD, Burney $\mathrm{P}$, Janson $\mathrm{C}$, et al. The prevalence and predictors of respiratoryrelated work limitation and occupational disability in an international study. Chest 2003:124:1153-9.

26. Eisner MD, Yelin EH, Katz PP, et al. Risk factors for work disability in severe adult asthma. Am J Med 2006;119:884-91.

27. Blanc PD, Cisternas M, Smith S, et al. Asthma, employment status, and disability among adults treated by pulmonary and allergy specialists. Chest 1996;109:688-96.

28. Ameille J, Pairon JC, Bayeux MC, et al. Consequences of occupational asthma on employment and financial status: a follow-up study. Eur Respir J 1997:10:55-8.

29. Meijster T, Tielemans E, Heederik DJ. Effect of an intervention aimed at reducing the risk of allergic respiratory disease in bakers: change in flour dust and fungal alpha-amylase levels. Occup Environ Med 2009;66:543-9.

30. Heijmans MJWM, Spreeuwenberg P, Rijken PM. Monitor zorg- en leefsituatie van mensen met astma en mensen met COPD; Trends en ontwikkelingen over de periode 2001-2004 (in Dutch). Utrecht: The Netherlands Institute for Health Services Research (NIVEL), 2005.

31. van Dijk C, Verheij R, Schellevis F. Hooikoorts in de huisartsenpraktijk: kosten en verleende zorg [Hay fever in the general practitioners office: costs and provided care](in Dutch). Utrecht: The Netherlands Institute for Health Services Research (NIVEL), 2010.

32. Cisternas MG, Blanc PD, Yen $\mathrm{IH}$, et al. A comprehensive study of the direct and indirect costs of adult asthma. J Allergy Clin Immunol 2003;111:1212-18.

33. Moscato G, Dellabianca A, Perfetti L, et al. Occupational asthma: a longitudinal study on the clinical and socioeconomic outcome after diagnosis. Chest 1999:115:249-56.

34. Ungar WJ, Coyte PC. Measuring productivity loss days in asthma patients. The Pharmacy Medication Monitoring Program and Advisory Board. Health Econ 2000;9:37-46.

35. Alexopoulos EC, Burdorf A. Prognostic factors for respiratory sickness absence and return to work among blue collar workers and office personnel. Occup Environ Med 2001; 58:246-52.

36. Godard P, Chanez P, Siraudin L, et al. Costs of asthma are correlated with severity: a 1-yr prospective study. Eur Respir J 2002;19:61-7.

37. Mellis CM, Peat JK, Bauman AE, et al. The cost of asthma in New South Wales Med J Aust 1991;155:522-8.

38. Lamb CE, Ratner $\mathrm{PH}$, Johnson CE, et al. Economic impact of workplace productivity losses due to allergic rhinitis compared with select medical conditions in the United States from an employer perspective. Curr Med Res Opin 2006;22:1203-10.

39. Malone DC, Lawson KA, Smith DH, et al. A cost of illness study of allergic rhinitis in the United States. J Allergy Clin Immunol 1997;99:22-7. 